\title{
PENCIPTAAN BUSANA HAUTE COUTURE DENGAN KONSEP BURUNG JALAK BALI
}

\author{
Drs. A.A. Anom Mayun K.T.,M.Si, Dewa Ayu Putu Leliana Sari, S.Pd., M.Sn Prodi Desain Mode, \\ Fakultas Seni Rupa dan Desain, ISI Denpasar, Jalan Nusa Indah, \\ Denpasar, Kode Pos 80235, Indonesia \\ anommayun@isi-dps.ac.id, dewaayuputulelianasari@gmail.com
}

\begin{abstract}
This paper is the result of the dissemination of p2s (research and art creation) in 2018 funded by DIPA ISI Denpasar which aims to create Haute couture clothing with the Bali starling concept made from traditional Balinese endek so that it can preserve the existing culture. The Bali starling is a native/ endemic bird owned by the island of Bali whose existence is rare and endangered. The characteristics of the Bali starling which inspired this creation are in the form of a beautiful song, as well as a stunning physique/appearance, having white fur all over its body except for the tip of the tail and wings which are black, and on the cheeks that are not covered with feathers. with a bright blue color, has a beautiful crest. The attractive beauty of the Bali Starling is manifested in the creation of haute couture or better known as haute couture, making haute couture clothing one of the best choices, because, in addition to being made with complicated sewing techniques, this clothing is also created specifically for certain groups, so that the product The resulting product cannot be marketed, not even easy to imitate and usually only created one piece and not reproduced. The method used in the creation of haute couture clothing is in the form of stages of exploration, design, and embodiment, but has been slightly adapted to the fashion design process. The results of his creation in the form of 5 pieces of haute couture clothing consisting of 3 women's clothing and 2 men's clothing. The use of endek cloth with pepatran motifs as the main material is a source of inspiration in the creation of haute couture clothing as an effort to preserve traditional Balinese fabrics which are currently not widely known by the public and many are extinct. Endek cloth has a characteristic variety of decoration and is under the socio-cultural values of each society.
\end{abstract}

Keywords: Creation, Haute couture, Jalak Bali

\begin{abstract}
Abstrak
Tulisan ini merupakan merupakan hasil luaran dari diseminasi p2s (penelitian dan penciptaan seni) pada tahun 2018 yang didanai oleh DIPA ISI Denpasar yang bertujuan untuk menciptakan Busana Haute couture dengan konsep Jalak Bali berbahan endek tradisional Bali sehingga dapat melestarikan budaya yang ada. Burung jalak Bali merupakan burung asli/endemic yang dimiliki oleh pulau Bali yang keberadaanya langka dan terancam punah. Ciri khas yang dimiliki jalak Bali yang menjadi inspirasi dalam penciptaan ini yaitu berupa kicauannya yang indah, serta fisik/penampilannya yang memukau, memiliki bulu yang putih di seluruh tubuhnya kecuali pada ujung ekor dan sayapnya yang berwarna hitam, serta pada bagian pipi yang tidak ditumbuhi bulu dengan warna biru cerah, mempunyai jambul
\end{abstract}


yang indah. Keindahan Jalak Bali yang menarik tersebut di wujudkan ke dalam penciptaan adibusana atau lebih dikenal dengan haute couture, menciptakan busana haute couture menjadi salah satu pilihan yang terbaik, karena selain dibuat dengan teknik penjahitan yang rumit, busana ini juga diciptakan khusus untuk kalangan tertentu, sehingga produk yang dihasilkan tidak mungkin pasaran, bahkan tidak mudah ditiru dan biasanya hanya diciptakan satu potong dan tidak

diperbanyak. Metode yang digunakan dalam penciptaan busana haute couture ini berupa tahapan eksplorasi, perancangan dan perwujudan, namun sedikit diadaptasi berkaitan dengan proses desain fashion. Hasil penciptaannya berupa 5 buah busana haute couture yang terdiri dari 3 busana wanita dan 2 busana pria. Penggunaan kain endek dengan motif pepatran sebagai material bahan utama merupakan sumber inspirasi dalam penciptaan Busana haute couture sebagai upaya untuk melakukan pelestarian kain-kain tradisional Bali yang dewasa ini tidak banyak diketahui oleh masyarakat dan banyak yang punah. Kain endek memliki ciri khas ragam hias dan penggunaannya yang sesuai dengan nilai-nilai sosial budaya setiap masyarakat.

Kata kunci: Penciptaan, Haute couture, Jalak Bali 


\section{PENDAHULUAN}

\section{Latar Belakang Masalah}

Indonesia memiliki berbagai macam kekayaan alam baik hayati, non hayati, flora dan fauna. Banyak diantaranya terancam punah ekosistemnya. Salah satu fauna endemic yang khas dimiliki oleh Indonesia yang kini keberadaannya terancam punah dan termasuk kategori satwa langka yaitu burung Jalak Bali (Sardjana,2019). Menurut Ardhana (2017), populasi burung jalak Bali terancam dalam kepunahan dari tahun ke tahun, dikarenakan cuaca/iklim global, habitat/ekosistem burung yang rusak, serta banyaknya perburuan liar. Burung Jalak Bali (Leucopsar rothschildi) dengan nama lokal, Curik Putih, merupakan salah satu Burung Asli Indonesia atau tepatnya Endemik Bali yang keberadaannya sangat di lindungi pemerintah sebagai satwa yang terancam punah.

Sejak tahun 1970, pemerintah Indonesia menggolongkan burung jalak Bali termasuk ke dalam hewan yang dilindungi berdasarkan SK Mentri Pertanian No. 421/Kpts/Um/8/70 dan sejak tahun 1966, hewan tersebut dimasukkan ke dalam data Red Book IUCN (International Union for Concervation of Nature and Natural Resource) sebagai hewan yang terancam punah. (Mas'ud,2010). Bali Bird Park (Taman Burung Bali) merupakan salah satu lembaga konservasi hewan di Bali yang telah melakukan penangkaran terhadap burung jalak Bali. Penangkaran ini sudah berhasil mengembangbiakkan burung jalak bali melalui program pengembangbiakannya (breeding). Bukti yang diperoleh dengan semakin meningkatnya jumlah burung jalak bali di Bali Bird Park dari 8 ekor menjadi 44 ekor.(Putra, 2014)

Hal tersebut dikarenakan banyaknya penangkapan/perburuan liar oleh orang yang tak bertanggung jawab serta berkurangnya habitat asli burung tersebut akibat dari kurang kesadarannya manusia dalam pembabatan hutan. Kekhasan yaitu eksotisnya burung Jalak Bali ini, dari segi kicauan dan fisik atau penampilanya memang sangat memukau. Jalak Bali memiliki ciri-ciri khusus, di antaranya memiliki bulu yang putih di seluruh tubuhnya kecuali pada ujung ekor dan sayapnya yang berwarna hitam. Bagian pipi yang tidak ditumbuhi bulu dengan warna biru cerah, mempunyai jambul yang indah.

Menurut Alfian, dkk (2019), Masyarakat di luar Pulau Bali dapat menjaga kelestarian burung jalak bali ini dengan cara memelihara dalam penangkaran, namun dengan syarat harus memiliki ijin resmi dan bersertifikat Balai Konservasi Sumber Daya Alam (BKSDA). Hal tersebut sebagai perlindungan burung jalak Bali sebagai hewan endemic langka pulau Bali, agar tidak diperjualbelikan secara illegal. Selain itu, pelestarian burung Jalak Bali di Taman Nasional Bali Barat harus dengan pengawasan yang ketat dalam upaya pelepasan kealam bebas, dan habitat/ekosistem yang telah dirusak perlu dibetulkan kembali. 
Keindahan Jalak Bali menarik untuk di wujudkan dalam penciptaan adibusana atau lebih dikenal dengan haute couture, menciptakan busana haute couture menjadi salah satu pilihan yang terbaik, karena selain dibuat dengan teknik penjahitan yang rumit, busana ini juga diciptakan khusus untuk kalangan tertentu, sehingga produk yang dihasilkan tidak mungkin pasaran, bahkan tidak mudah ditiru dan biasanya hanya diciptakan satu potong dan tidak diperbanyak.

Busana berkaitan dengan sikap dan tingkah laku manusia, yang merupakan perlambang dari peran seseorang dan status sosialnya. Didalamnya terkandung penghargaan terhadap pengakuan, pembenaran dan identifikasi si pemakai. Para wanita biasanya akan menggunakan busana yang mencolok untuk menarik orang melihat, busana haute couture adalah pilihan yang tepat.

Busana ini memiliki kesatuan desain dari setiap busananya namun dengan karakter yang unik dan berbeda, sehingga penggunanya menjadi percaya diri dengan penampilannya. Dilihat dari penggunaan bahan yang digunakan untuk busana haute couture bermacam-macam mulai bahan kain, kulit imitasi dan kulit alami, maupin bahan- bahan alami yang bisa diperoleh disekitar kita salah satunya adalah penggunaan kain tradisional Bali yaitu endek. Penggunakan kain endek sebagai bahan utama dan bahan penunjang dapat melestarikan budaya daerah setempat, sehingga semakin banyak yang mengetahui bahwa kain endek tidak hanya digunakan sebagai sarana upacara, tetapi bisa juga dipergunakan sebagai busana dan bahan busana. Penggunaan Kain endek sebagai penciptaan Busana haute couture dapat meningkatkan kreatifitas sehingga dapat menghasilkan rancangan Busana malam yang inovatif.

Penggunaan kain endek sebagai sumber inspirasi dalam penciptaan busana haute couture sebagai upaya untuk melakukan pelestarian kain-kain tradisional Bali yang dewasa ini tidak banyak diketahui.

oleh masyarakat dan banyak yang punah. Kain endek memliki ciri khas ragam hias dan penggunaannya yang sesuai dengan nilainilai sosial budaya setiap masyarakat. Ragam hiasnya merupakan suatu paduan konsepsi berbagai ide yang mencerminkan hubungan manusia dengan lingkungan alam, hubungan manusia dengan peristiwa-peristiwa hidupnya , dan hubungan manusia dengan apa yang ada di sekeliling tempat tinggalnya.

\section{Rumusan Masalah}

Bagaimana merancang busana haute couture dengan konsep Burung Jalak Bali ?

\section{Tujuan Perancangan}

Tujuan perancangan pada penelitian dan penciptaan seni, yaitu sebagai berikut : Mewujudkan atau merancang desain busana haute couture dengan konsep Burung Jalak Bali 
menggunakan bahan kain endek Bali.

\section{Batasan Perancangan}

Batasan perancangan pada penelitian dan penciptaan seni adalah sebagai berikut :

1. Batasan keilmuwan : yakni ruang lingkup desain mode.

2. Batasan material : yakni menggunakan kain tenun endek motif pepatran

3. Batasan pasar :

- Geografis : yakni berfokus pada wanita Indonesia khusus wilayah Jakarta dan Bali

- Demografis : berfokus pada wanita yang sudah mapan sekitar 35-50 tahun (kelas sosialita)

\section{Tinjauan Data Busana Haute couture}

Menurut Posner dalam Leliana (2014), yang memaparkan tentang busana haute couture merupakan suatu tingkatan fashion tertinggi dengan jahitan yang berkualitas baik.

Rancangan adibusana atau lebih dikenal dengan istilah bahasa Prancis Haute couture merupakan teknik pembuatan pakaian tingkat tinggi yang dibuat khusus untuk pemesannya, menggunakan bahan-bahan berkualitas terbaik, biasanya dihiasi detail, dikerjakan dengan tangan, dan pembuatannya memakan waktu lama. haute couture atau adibusana adalah istilah yang digunakan untuk keadaan dimana sebuah pakaian dibuat secara eksklusif berdasarkan permintaan khusus (made to order). Busana haute couture berada pada klasisfikasi hirarki dasar tingkatan fashion tertinggi di atas high end fashion, middle market, mass market dan value market discount retailers.

Biasanya terbuat dari bahan dengan kualitas tinggi, perhatian akan detail yang luar biasa, dan pengerjaannya yang memakan waktu karena hanya menggunakan tangan dan tanpa mesin. Adibusana, biasanya hanya diciptakan satu potong (one and the only piece) dan tidak untuk diperbanyak. Oleh karena itu, pembuatan karya rancangan adibusana dianggap penting baik bagi sang perancang; bagi para pekerja rumah mode yang bersangkutan mulai dari juru gambar, tukang potong, tukang jahit hingga para peraga (model) yang dikontraknya; dan terutama penting bagi para konsumen mode yang niscaya bersedia mengenakan haute couture berharga mahal demi eksklusifitas.

Adibusana merupakan busana adiluhung dengan desain orisinal atas pesanan pelanggan, dibuat secara eksklusif dengan kriteria khusus, bahan bermutu prima, teknik pembuatan pola menggunakan patung (pattern draping), dibuat baju contohnya (toile), dilakukan pengepasan, proses pengerjaan $80-90 \%$ dengan tangan dengan ketelitian terhadap setiap detail, tampak apik di bagian luar maupun dalam busana.

Persepsi keliru sering terjadi pada istilah "adibusana" terutama bila menyangkut baju pesta atau baju malam. Pengertian "adibusana" sebenarnya tidak berkaitan 
dengan jenis busana melainkan lebih pada eksklusivitas bahan, desain, serta kriteria pengerjaan (Hadisurya, 2011.

Menurut Triajatnika (2017), adapun kekurangan dan kelebihan adi busana (haute couture); kelebihanny yaitu, proses pembuatan sebuah adi busana dari proses awal harus dilakukan dengansekitar $85 \%$ buatan tangan dan bukan bantuan mesin, pembuatan pakaian berteknik adi busana membutuhkan waktu yang cukup lama, dan tidak dibuat dalam jumlah yang banyak. Sedangkan kelebihan yaitu: desain dan proses yang eksklusif, menggunakan material bahan yang berkualitas tinggi, mahal, dan dijahit dengan tingkat ketelitian yang tinggi oleh para penjahit adi busana profesional. Di dunia mode, adi busana/haute couture merupakan tingkat/level rancangan paling tinggi, dan busana couture terkesan lebih megah dan bercitra seni.

Berikut merupakan Desainer fesyen Indonesia dan dunia yang merancang busana haute couture yaitu:

\section{Burung Jalak Bali}

Burung jalak Bali ditemukan pertama kali oleh Dr. Baron Stresemmen pada tanggal 24 Maret 1911. (Mas'ud, 2010). Sedangkan nama ilmiah Jalak Bali dinamakan menurut pakar hewan berkebangsaan Inggris, Walter Rothschild, sebagai orang pertama yang mendeskripsikan spesies ini ke dunia pengetahuan pada tahun 1912. Burung ini termasuk ke dalam family Sturnudae dan tergabung dalam genus Leucopsar, dan spesies Leucopsar rothschildi. Ciri-ciri morfologis burung jalak Bali adalah sebagai berikut :

- Bulunya $80 \%$ berwarna putih bersih, pada ujung bulu sayap dan bulu ekornya ditemukan warna hitam lebarnya sekitar $25 \mathrm{~mm}$.

- Pelupuk matanya berwarna biru tua mengelilingi bola mata, paruh runcing dengan panjang 2-3 cm, di bagian ujungnya berwarna kuning kecoklatan, rahangnya berwarna abuabu kehitaman.

- Burung jantan bentuknya lebih indah, mempunyai jambul di kepalanya dengan beberapa helai bulu berwarna putih bersih. Walaupun sebenarnya burung ini termasuk monomorfik yang artinya bentuk luar tubuh (morfologi) burung jantan dan betina susah diibedakan karena memiliki warna bulu, bentuk dan ukuran tubuh yang hampir sama (burung jalak betina agak sedikit besar dibandingkan jantan).

- Panjang tubuhnya dari ujung paruh sampai ujung ekor kurang lebih $25 \mathrm{~cm}$, panjang paruh $3 \mathrm{~cm}$ dengan bentuk meruncing, panjang kepala $5 \mathrm{~cm}$, panjang leher $2 \mathrm{~cm}$, panjang sayap $13 \mathrm{~cm}$, panjang ekor $6 \mathrm{~cm}$, dengan warna kehitaman (black spotted) di ujung sayap sepanjang $2 \mathrm{~cm}$ dan panjang kaki (tidak termasuk paha) $4 \mathrm{~cm}$.

- Berat badan 107,75 gram, jumlah bulu sayap 11-12 helai dan jumlah bulu ekor 1718 helai. 


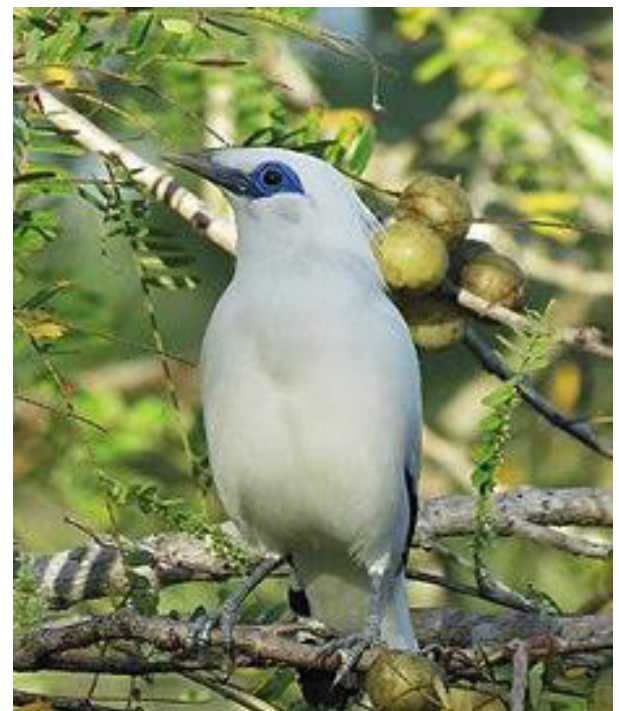

Gambar 1. Burung jalak Bali

Sumber: (https://id.wikipedia.org/wiki/Jalak_bali)

Karakteristik pohon pemanfaatan oleh burung Jalak Bali (jenis vegetasi) yaitu

Tabel 1. Jenis vegetasi yang digunakan oleh jalak Bali Sumber: (Nirmala Ayu Aryanti dan Reyza Hermawan, 2018)

\begin{tabular}{|l|c|}
\hline \multicolumn{2}{|c|}{ Tanjung Gelap } \\
\hline \multicolumn{1}{|c|}{ Jenis Pohon } & Jumlah \\
\hline Rhizophora apiculata Lamk & 2 \\
\hline Zizyphus mauritiana Lamk & 2 \\
\hline Ficus glabella Roxb & 6 \\
\hline Acacia leucopliaa Willd & 24 \\
\hline Coneratia alba & 1 \\
\hline Albizzia lebbeckoides Merr & 1 \\
\hline Grewia koordersiana & 16 \\
\hline Schoutenia ovata & 4 \\
\hline JUMLAH & 56 \\
\hline \multicolumn{2}{|c|}{ Jenis Pohon } \\
\hline Acacia aurikuliformis Willd & Jumlah \\
\hline Tamarindus indica L. & 7 \\
\hline \multicolumn{2}{|c|}{ Lalang } \\
\hline Azadiractha indica & 1 \\
\hline Mangifera indica L. & 28 \\
\hline Acacia leucopliaa Wild & 5 \\
\hline Laneaa coromandelica Merr & 6 \\
\hline Manilkara kauki Dub & 6 \\
\hline JUMLAH & 68 \\
\hline
\end{tabular}

Burung jalak Bali menyukai hidup di hutan savana, mangrove, rawa, dan hutan musim dataran rendah. Kondisi iklim yang normal serta curah hujan cukup, dan musim tanaman buah sangat menentukan populasi dari burung jalak Bali tersebut. Dalam Ardhana (2017) disebutkan, habitat burung jalak Bali terdapat pada lubanglubang pohon yang tingginya sekitar 2,5 $m-7 m$ dan memiliki sarang yang berdiameter $10 \mathrm{~cm}$ dengan bahan sarang berupa rerumputan kering dan ranting semak. Pada umumnya makanan dari burung jalak Bali ini adalah beberapa macam serangga (ulat, belalang, semut, jangkrik dan rayap). Sedangkan jenis buah-buahan yang menjadi sumber pakannya biasanya berdasarkan musimnya ada beberapa jenis yaitu kerasi, kemloko, intaran, walikukun, buni, laban kalak, kesambi, murbei, pisang, papaya dan bidara.

Perilaku burung jalak Bali suka terbang secara berkelompok atau bergerombol. Pergerakan burung jalak Bali sebatas lingkungan/habitat yang ada sumber makanannya. Pada waktu siang hari, burung ini terbang ke sekitar tepi pantai atau sumber mata air yang lain untuk mencari minum dan mandi. Periode bertelur burung ini berkisar antara bulan Januari hingga Maret sebanyak berkisar 3 butir telur. Proses pengeraman burung jalak Bali terjadi selama 1517 hari secara bergantian antara jantan dan betina. Namun tidak semua telur tersebut dapat menetas, hanya 1 butir yang menetas. Itulah alasan burung jalak Bali ini terancam punah, karena susah dalam mengembangkan populasi burung jalak Bali. 


\section{Kain Endek Dengan Motif Pepatraan}

Kain endek merupakan kain atau wastra tradisional Bali, dimana proses pembuatan endek membutuhkan waktu yang cukup lama untuk satu motif kain endek. Salah satu motif dari kain endek yaitu motif pepatraan banyak diambil dari bentuk-bentuk keindahan flora.

Keindahan flora diambil sedemikian rupa sehingga jalur daun, bunga, putik dan ranting dibuat berulang-ulang. Masing-masing Patra memiliki identitas yang kuat untuk penampilannya sehingga mudah diketahui.

a. Patra Wangga, kembang mekar atau kuncup dengan daun-daun lebar divariasi lengkunglengkung keserasian yang harmonis. Batang-batang bersulur di sela-sela bawah bunga dan daun-daun.tergolong kekerasan yang merupakan sebagian dari suatu flora dengan penampilan bagian-bagian keindahannya.

b. Patra Sari Bentuknya menyerupa flora dari jenis berbatang jalar melingkarlingkar timbal balik berulang. Penonjolan sari bunga merupakan identitas pengenal sesuai namanya. Daun-daun dan bungabunga dilukiskan dalam pater-patern yang diperindah. atra sari dapat digunakan pada bidang-bidang lebar atas, dan umumnya untuk bidang-bidang sempit tidak banyak dapat divariasi karena lingkar-lingkar batang jalar, daun-daun sari kelopak dan daun bunga merupakan pola-pola tetap sebagai identitas.

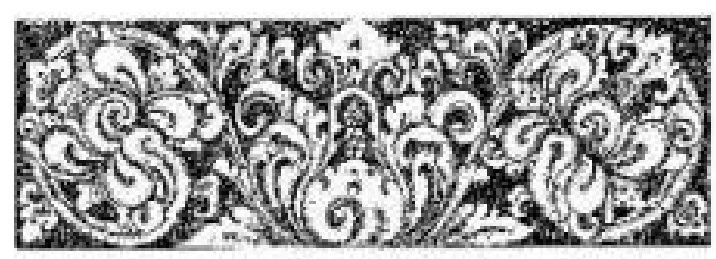

Gambar 2. Patra Sari Sumber: (I Made Suparta, 2010)

c. Patra Bun-bunan, dapat bervariasi dalam berbagai jenis flora yang tergolong bunbunan (tumbuh-tumbuhan berbatang jalar). Dipolakan berulang antara daun dan bunga dirangkai batang jalar. Dapat pula divariasi dengan julur-julur dari batang jalar

d. Patra Pidpid ,juga melukiskan flora dari jenis daun bertulang tengah dengan daun-daun simetris yang dapat bervariasi sesuai dengan jenis daun yang dilukiskan penempatannya pada bidang- bidang sempit.

e. Patra Punggel, mengambil bentuk dasar liking paku, sejenis flora dengan lengkunglengkung daun muda pohon paku. Bagianbagiannya ada yang disebut batun poh, kuping guling, util sebagai identitas Patra Punggel.

Pola patern patra punggel merupakan pengulangan dengan lengkung timbal balik atau searah pada gegodeg hiasan sudutsudut atap bangunan.Dapat puladengn pola mengembanguntuk bidang-bidang lebar ataubervariasi/combinasi dengan patra lainnya. 

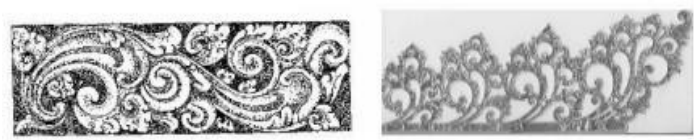

Gambar 3. Patra Punggel Sumber: (I Made Suparta, 2010)

f. Patra Samblung, pohon jalar dengan daundaun lebar dipolakan dalam bentuk patern yang disebut Patra Samblung. Ujung-ujung pohon jalar melengkung dengan kelopak daun dan daun- daun dihias lengkunglengkung harmonis.

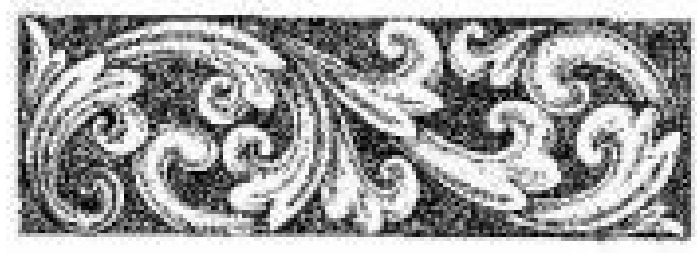

Gambar 4. Patra Samblung Sumber: (I Made Suparta, 2010)

g. Patra Pae, mengambil bentuk tumbuhtumbuhan sejenis kapu-kapu yang dipolakan berulang dalam deretan memanjang.

h. Patra Ganggong, menyerupai bentuk tumbuh-tumbuhan ganggang

air yang dipolakan dalam bentuk berulang berjajar memanjang.

i. Patra Batun Timun, bentuk dasar serupa biji mentimun yang dipolakan dalam susunan diagonal berulang. Sela-sela susunan dihias dengan bentuk-bentuk patra masmasan setengah bidang.

j. Patra Sulur, melukiskan pohon jalar jenis beruas-ruas dengan daun-daun sulur bercabang- cabang tersusun berulang.
Patra sulur dipolakan pula dalam bentuk tiga jalur batang jalar teranyam berulang.

k. Patra bun dengan motif mengambil bentuk dasar yang menyerupai patra wangga patra punggel patra Sari, patra Samblung. Bentuk-bentuk dasar divariasi dengan motif-motif ceritera pewayangan, ceritera rakyat, ceritera dari dunia fauna atau dengan gabungan beberapa patra yang disesuaikan. (Gelebet, 1986)

\section{Unsur Desain dalam Merancang Busana}

Unsur desain dalam merancang desain busana, dimana busana merupakan kebutuhan dasar manusia yang tidak dapat ditinggalkan dalam kehidupan manusia. Dilihat dari fungsinya busana melindungi tubuh dari pengaruh alam, menyesuaikan dengan peradaban dimana manusia tinggal serta dapat membuat penampilan seseorang lebih tampan atau menarik.

Melihat fungsi busana ada beberapa unsur yang perlu diperhatikan dalam mendesain sebuah busana. Adapun unsur tersebut adalah (Riyanto, 2003):

a. Garis

Garis merupakan penghubung dua buah titik, dalam mencipta sebuah busana garis sebagai salah satu unsur yang diperlukan dan mempengaruhi sesuatu mode busana sebagai bayangan garis sisi luar dari model busana yang disebut siluet, garis hiasan.

b. Arah

Arah dan garis saling berkaitan, karena 
semua garis mepunyai arah yaitu vertikal, horizontal, diagonal dan lengkung. Tiap arah mempunyai kesan berbeda Garis vertikal memberi kesan agung, garis horizontal memberi kesan perasaan tenang, garis diagonal dan garis miring memberi kesan dinamis, garis lengkung memberi kesan luwes, bersifat riang dan gembira.

c. Bentuk

Mencipta sebuah desain busana malam akan didasarkan pada beberapa bentuk yang umumnya disebut bentuk geometris dan bentuk lainnya sebagai variasi pada figure seseorang. Bentuk dapat diterapkan sebagai bentuk busana atau sebagai struktur atau sebagai dekoratif

d. Ukuran

Pada sebuah desain busana, bentuk, garis sering berbeda ukuran. Ukuran ini harus diperhatikan karena mempengaruhi hasil desain. Unsur -unsur desain yang diperhatikan pada sebuah desain perlu mempunyai ukuran yang seimbang, sehingga menjadi satu kesatuan yang serasi harmonis baik kesatuan desain, maupun dengan pemakai busana tersebut

e. Warna dan motif kain

Warna dan motif kain memegang peranan penting dalam mendesain busana. Pemilihan warna dan motif kain yang tepat untuk desain busana malam menentukan keindahan dan keharmonisan.

Warna dan motif kain juga memperngaruhi kesan gemuk atau kurus pada saat pemakai menggunakan busana.

f. Nilai

Nilai berkaitan dengan warna yaitu warna tergelap sampai dengan warna terang. Warna-warna tersebut memiliki nilai tertentu yang mampu memberikan kesan suasana.

g. Tekstur

Tekstur sangat penting dalam mendesain sebuah busana. Pemilihan tekstur sebaiknya disesuaikan dengan model yang dirancang. Jenis-jenis tekstur adalah tekstur kaku, tekstur kasar dan halus, tekstur lemas, tekstur tembus pandang dan tekstur mengkilap dan kusam.

\section{Prinsip Desain Busana dalam Busana}

a. Kesatuan

Desain yang baik selalu memperhatikan keselaran diantara macam-macam unsur desain yaitu seklaras garis dan bentuk selaras dalam tekstur dan warna sehingga menghasilkan desain busana yang harmonis.

b. Keseimbangan

Keseimbangan dalam mendesain adalah untuk mendapatkan ketenangan dan kestabilan. Pengaruh ketenangan ini dapat menimbulkan perhatian yang sama antara kiri dan kanan atau terpusat pada salah satu sisi.

c. Proporsi

Proporsi dalam sebuah desain adalah cara menempatkan unsur-unsur atau bagianbagian busana dan aksesoris yang berkaitan dengan jarak, ukuran, jumlah, tingkatan 
atau bidang pada suatu model busana.

d. Irama

Irama pada suatu desain aksesoris merupakan suatu pergerakan yang teratur dari suatu bagian ke bagian lainnya, sehingga dapat dirasakan dengan penglihatan.

e. Pusat perhatian

Desain harus mempunyai pusat perhatian atau suatu bagian yang menarik dibandingkan dari bagian-bagian yang lainnya. Pusat perhatian tersebut bisa pada bagian depan busana atau pada bagian pegangan sesuai dengan konsep yang dinginkan.

\section{Metode Penciptaan}

Metode/proses penciptaan merupakan cara mewujudkan karya seni secara sistematik. Bertujuan untuk menghasilkan karya desain fashion yang ideal dan dapat dipertanggung jawabkan. Metode yang digunakan dalam penciptaan ini menurut S.P Gustami (2007) yaitu tahap eksplorasi, perancangan dan perwujudan, namun sedikit diadaptasi berkaitan dengan proses desain fashion. Adapun tahapan dalam proses penciptaan karya desain busana malam nampak pada gambar dibawah ini, yaitu:

\section{Tahap Eksplorasi}

Tahapan eksplorasi merupakan kegiatan awal dalam merancang suatu karya seni. Di tahapan ini seorang desainer, menemukan konsep dan menggali ide dari konsep tersebut. Pada rancangan busana haute couture ini, menitik beratkan pada ciri khas burung jalak bali yang berwarna putih dalam hal ini burung endemic pulau Bali. Pulau Bali sendiri identic dengan kain tradisional yaitu endek dengan motif-motif ciri khas ornmen pepatran Bali.

2. Tahap Perancangan ; Menggambarkan Ide Perancang busana adalah orang yang memiliki keinginan untuk membuat sesuatu. la mengkombinasikan pengetahuan dalam prakteknya dengan kemampuan artistik untuk mengubah ide-ide yang abstrak menjadi sebuah desain formal untuk pakaian dan barang-barang yang nantinya akan dikenakan oleh konsumen.

Pada tahapan perancangan seorang desainer, memperoleh berbagai inspirasi dari berbagai sumber sehingga akhirnya muncul ide-ide untuk membuat suatu koleksi rancangan, tahap berikutnya bagi seorang perancang busana adalah mengilustrasikan ide mereka ke atas kertas. Terdapat dua pendekatan dalam menuangkan gambar mode, yaitu gambar bebas dan gambar skematik:

1. Gambar Bebas

Gambar bebas menunjukkan bagaimana pakaian yang dirancang seharusnya digunakan apabila diaplikasikan pada tubuh. Biasanya proporsi tubuh mengalami distorsi, dengan kepala tergambarkan kecil, leher dan kaki lebihpanjang dari proporsi badan yang sebenarnya. 
Apabila penggambaran anatomi biasa sebuah badan wanita terbagi atas $7 \frac{1}{2}$ kepala, maka dalam gambar mode, anatomi badan wanita dapat terbagi hingga $8 \quad 1 / 2$ atau 9 kepala.Bagian kaki digambarkan secara berlebihan panjangnya dibandingkandengan bagian torso. Dan karena bertujuan untuk menonjolkan pakaian rancangan, maka penggambaran tubuh dilebih- lebihkan agar membentuk ruang untuk detil-detil pakaian, seperti kantong dan garis-garis jahitan.

2. Gambar Skematik

Gambar skematik merupakan gambar yang datar, dimana penggambaran pakaian rancangan digambarkan dengan jelas dan diagramatis untukmenunjukkan detildetil teknis rancangan tersebut. Gambar semacam ini tidak disajikan persis sesuai dengan gambar anatomi tubuh manusia. Setiap garis jahitan, konstruksi dan detil potongan memang digambarkan, namuntanpa pewarnaan dan bayangan agar menghindari kesalahan dalam proses produksi. Biasanya gambar skematik ini disajikan pada tahap proses produksi, yakni ditunjukkan kepada penjahit dengan maksud agar lebih mudah bagi penjahit dan juru potong untuk menginterpretasikan rancangan pakaian tersebut. Pada gambar skematik, ukuran badan, bahu, panjang dan lebar lengan, ukuran kerah hingga kantong biasanya digambarkan dengan proporsi yang benar.
Berikut gambar skematik daalam penciptaan busana, yaitu :

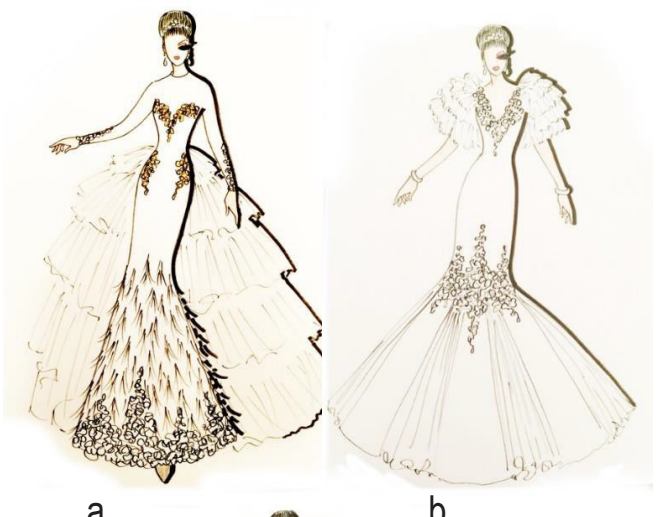

a

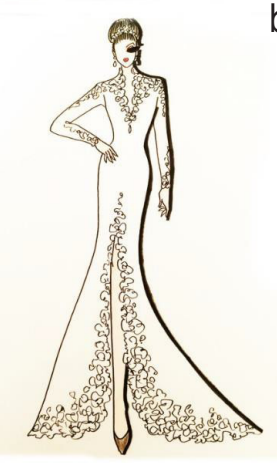

C

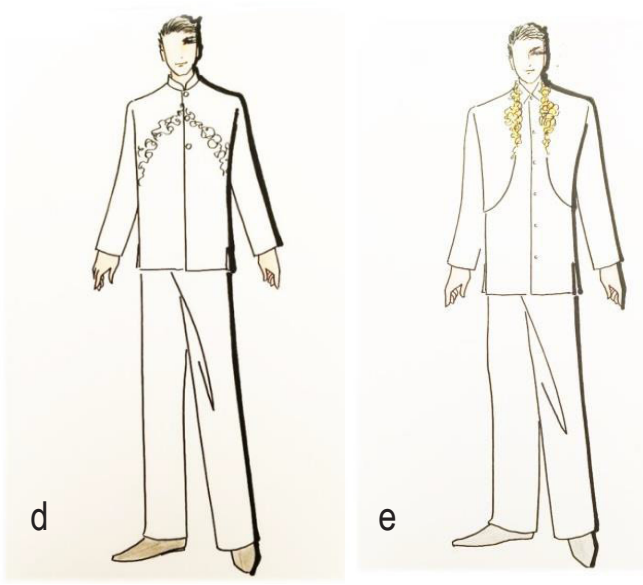

Gambar 5 a,b,c merupakan gambar ilustrasi desain busana haute couture wanita, serta d dan e merupakan gambar ilustrasi desain busana haute couture pria Sumber: (Anom Mayun, 2018) 
Mencari bahan yang cocok merupakan salah satu kunci kesuksesan dalam merancang sebuah karya rancangan busana. Tak hanya persoalan visualisasi bahan itu sendiri, melainkan juga berat dan pemeliharaannya, serta harga, motif atau cetakan perancang busana harus memiliki ekspektasi yang beralasan mengenai bagaimana perilaku bahan tersebut; contohnya, sebuah bahan tidak bisa dipaksakan menyatu dalam gaya potongan pakaian tertentu, atau bentuk tertentu,apabila tidak cocok dengan karakteristik bahan tersebut. Memilih bahan merupakan salah satu pekerjaan paling sulit yangharusdilakukan para perancang busana sekaligus merupakan pekerjaan paling pentingdalam proses pembuatan suatu koleksi pakaian.

Dalam proses penciptaan karya ini, pencipta meelakukan eksplorasi bahan di daerah Klungkung yng dikenal sebagai sentra kain endek. Eksperimen pada bahan kombinasi bahan wool dengan warna putih dipadukan dengan kain brokat dan toile.

Deorang perancang busanaharus senantiasa mengingat bahwa suatu rancangan pakaian dengan bahan yangdigunakannya tidak boleh saling bersaing untuk menjadi pusat perhatian. Rancangbentuk dan bahan rancangan justru harus dapat saling mengisi demi memperindahkarya rancangan busana tersebut.

\section{Tahap Perwujudan ; Membuat Pola}

\section{Pakaian dan Proses Penjahitan}

Proses pemotongan pola ini merupakan proses yang terpenting dalam pembuatan pakaian, karena pada proses ini terjadi pemotongan bahan (yang eksklusif)sehingga kesalahan harus diminimalisasikan.

Biasanya tukang pola menggantungkanbahan yang akan digunakan untuk pembuatan pakaiannya ke atas manekin(mannequin), hal ini dilakukan agar tukang pola dan sang perancang dapat melihat gambaran bagaimana "jatuhnya" bahan terhadap badan apabila nantinya sudah rampung. Setelah pola dipasangkan pada manekin dan dilakukan beberapa koreksiapabila terjadi beberapa kesalahan dalam pemotongan atau ukuran pakaian, barulah pola tersebut diberikan kepada tukang jahit untuk nantinya dijahit untuk berbeda dengan pakaian adibusana, yang penjahitannya cenderung merupakan gabungan antara jahitan menggunakan tangan dan mesin jahit . pakaian adibusana memiliki detil yang cukup rumit dan hanya bisa dijahit satu-persatu dengan menggunakan tangan. Belum lagi jika pakaian tersebut membutuhkan tambahan detil seperti payet, bordir, dan lain sebagainya.

Pada proses fitting, atau disebut juga dengan proses pengepasan pakaian pada 
tubuh, perancang sudah mendapatkan hasil pakaian yang sudah rampung. Namunyang masih ingin dicari adalah apabila pakaian ini dikenakan pada tubuh manusia,sang model dapat bergerak dengan baik atau tidak, apakah terdapat kesulitan berjalanatau tidak. Oleh karena itu, pada proses ini perancang harus melaksanakan inspeksi menyeluruh terhadap pakaian (quality control). Apabila terjadi kesalahan, maka jahitan pada bagianyang salah tersebut harus dibuka kembali dan dibetulkan.

Proses terakhir adalah menyetrika pakaian dan membetulkan jahitan, apabilaterdapat jahitan yang masih belum rapi. Selanjutnya bagian yang jahitannyadibetulkan tersebut harus disetrika kembali agar terlihat rapi. Penempatan kancing, restleting, pita dan lain sebagainya dilakukan pada proses ini.

\section{Wujud Karya}

Pakaian wanita yang dibuat hendaklah dapat menonjolkan sisi feminim dari wanita dan dapat menonjolkan kelebihan yang dimilikinya sehingga dalam berpenampilan terlihat cantik, rapi dan menarik. Desain digambarkan dengan gaya berdiri menghadap kedepan atau miring tiga per empat. Perbandingan letak bagianbagian busana pada sikap berdiri model akan lebih memudahkan kita memahami desain pakaian yang akan dibuat, berikut adalah hasil dan luaran dari penciptaan busana haut coutre dengan mengamil ide Jalak Bali.

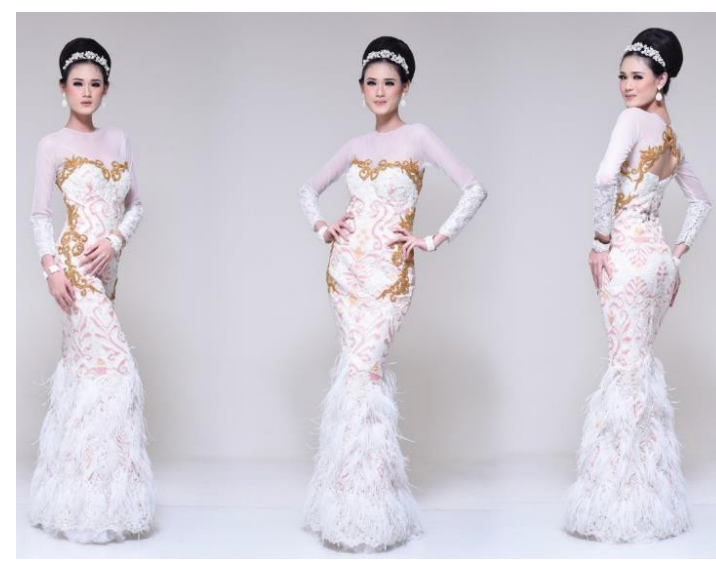

Gambar 6. hasil perwujudan desain 1 Sumber : (Anom Mayun, 2018)

Busananya sudah pasti menggunakan bahan berkualitas dengan permainan motif dan warna yang menarik, perpaduan warna dasar dan motif kain endek memberikan kesan yang indah. Variasi bulu mercy di tempatkan pada rok bagian bawah untuk menciptakan tampilan yang lebih kontemporer dan disukai. gaun yang di desain dengan siluet sheath (ramping).

Siluet tersebut dipilih karena dapat memperjelas lekuk badan. Pada bagian belakang gaun diberi ekor berbahan tulle untuk memberi kesan glamour. Motif pepatraan sendiri dikomposisikan pada bagian depan gaun agar antara bagian depan dan belakang gaun seimbang, serta penambahan peplum pada bagian pinggang ditujukan agar pinggang terlihat lebih ramping dan pinggul lebih berisi. Gaun model 1 ini dibuat sesuai dengan desain awal, namun ada sedikit penambahan payet pada line bagian dada dan pada sisi tile bagian ekor sebagai garis penegas. 


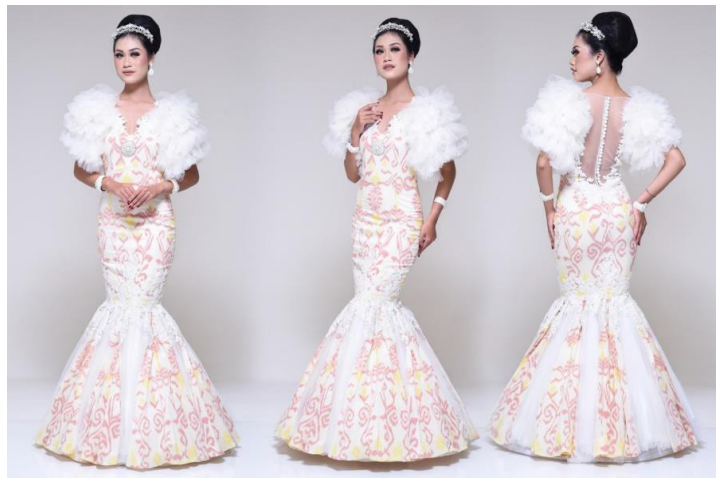

Gambar 7. hasil perwujudan desain 2 Sumber : (Anom Mayun, 2018)

Gaun model 2 didesain menggunakan siluet mermaid (duyung). Siluet ini digunakan selain karena dapat mempejelas lekuk badan juga dapat memberi kesan elegan yang sangatanggun. Dengan motif pepatraan yang ditabur di atas tulle membuat gaun ini lebih cantik. Gaun ini dibuat sesuai dengan desain awal. Hanya ada sedikit perubahan motif pada bagian rok dan bagian belakang atasan. Perubahan motif tersebut dilakukan agar motif tidak terlihat monoton.

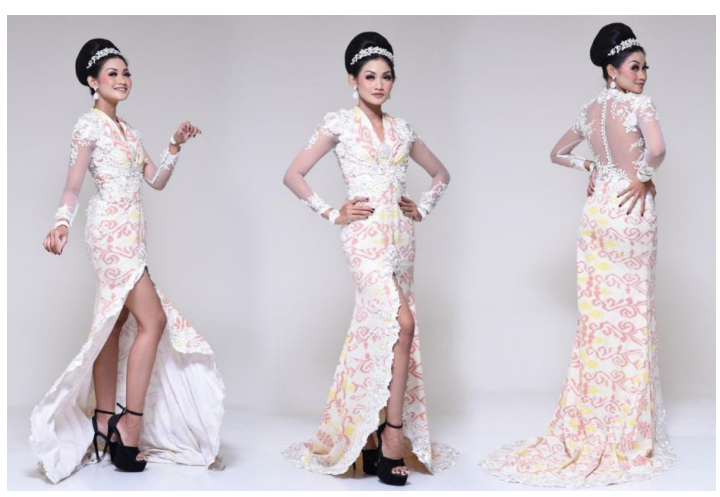

Gambar 8. hasil perwujudan desain 3 Sumber : (Anom Mayun, 2018)

Gaun model 3 dengan model bagian punggung berbahan tulle dan ditabur motif pepatraan juga belahan depan pada rok menggunakan bahan brokat membuat gaun terkesan elegan seksi. Gaun ini juga menggunakan siluet sheath agar memperjelas lekuk tubuh namun kali ini ditambah dengan hiasan bahan tulle pada bagian samping sebagai penyeimbang belahan dan motif pada sisi lainnya. Gaun ini dibuat sesuai dengan desain awal. Hanya sedikit perubahan ukuran peplum samping yang pada awalnya lebih panjang

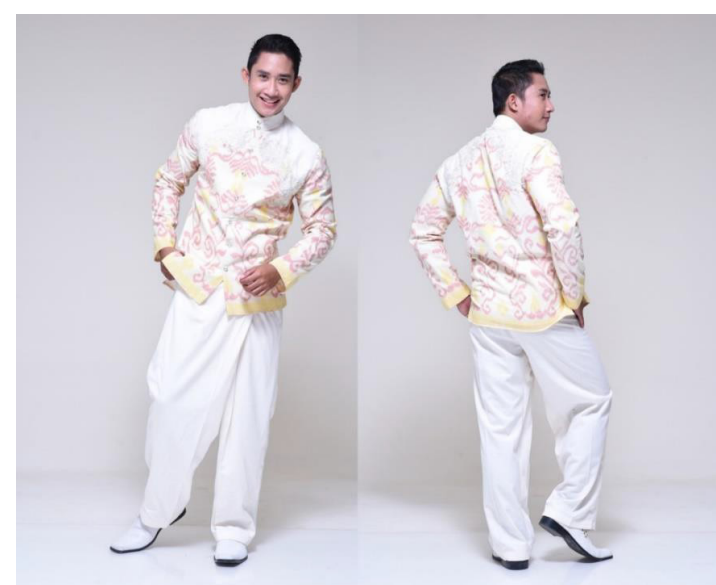

Gambar 9. hasil perwujudan desain 4 Sumber : (Anom Mayun, 2018)

Kemeja merupakan dasar klasik dari segala model kemeja untuk pria mempunyai bentuk krah standar yaitu krah dengan penegaknya, lengan panjang dengan manset. Kemeja salah satu busana bagian atas untuk pria.

Tingkat kesulitan kemeja lengan panjang terletak pada hasil krah dan manset. Kemeja yang mempunyai kwalitas baik akan ditentukan oleh penjahitan krah dan manset. Untuk menambah kesan gagah dan glamour diberikan aplikasi moyif yang hampir mirip dengan motif kain endek. 


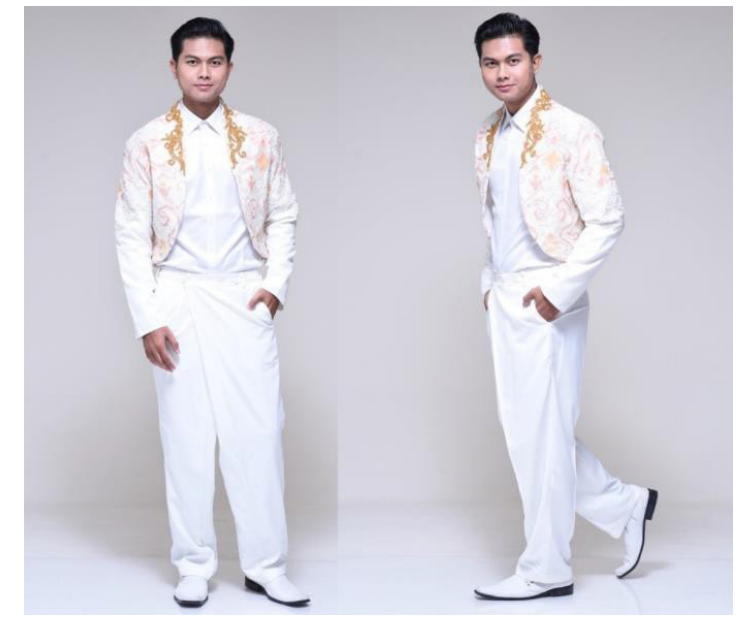

Gambar 10. hasil perwujudan desain 5 Sumber : (Anom Mayun, 2018)
Pada desain 5 ingin menampilkan busana couture bagi pria dengan style bolero dan penambahan payet pada shoulder untuk memberikan kesan glamour pada pemakainya. Memadukan unsur modern atau yang terbaru dengan pakem jahitan khas dan penambahan aplikasi payet pada bagian bahu.

\section{Penerapan Unsur Desain dalam Desain Busana}

Berikut merupakan unsur desain dalam desain busana haute couture dengan konsep Burung Jalak Bali menggunakan bahan kain endek Bali, yaitu:

\begin{tabular}{|l|l|l|l|l|l|}
\hline $\begin{array}{l}\text { Unsur } \\
\text { Desain }\end{array}$ & Desain 1 & Desain 2 & Desain 3 & Desain 4 & Desain 5 \\
\hline Garis & lengkung & lengkung & lengkung & lengkung & lengkung \\
\hline Arah & vertikal & vertikal & horizontal & $\begin{array}{l}\text { Vertical \& } \\
\text { diagonal }\end{array}$ & $\begin{array}{l}\text { Vertical \& } \\
\text { diagonal }\end{array}$ \\
\hline Bentuk & Siluet T & $\begin{array}{l}\text { Siluet } \\
\text { hourglass }\end{array}$ & Siluet L & $\begin{array}{l}\text { Kombinasi } \\
\text { antara Siluet T } \\
\text { dan pant's siluet }\end{array}$ & $\begin{array}{l}\text { Kombinasi } \\
\text { antara Siluet T dan } \\
\text { pant's siluet }\end{array}$ \\
\hline Ukuran & Size M wanita & Size M wanita & Size M & Size M pria & Size M pria \\
\hline
\end{tabular}

\begin{tabular}{|c|c|c|c|c|c|}
\hline & & & wanita & & \\
\hline $\begin{array}{l}\text { Warna } \\
\text { dan Motif } \\
\text { Kain }\end{array}$ & $\begin{array}{l}\text { Warna dominan } \\
\text { putih dan motif } \\
\text { endek pepatran } \\
\text { warna pastel }\end{array}$ & $\begin{array}{l}\text { Warna } \\
\text { dominan putih } \\
\text { dan motif } \\
\text { endek } \\
\text { pepatran warna } \\
\text { pastel }\end{array}$ & $\begin{array}{l}\text { Warna } \\
\text { dominan } \\
\text { putih dan } \\
\text { motif } \\
\text { endek } \\
\text { pepatran } \\
\text { warna pastel }\end{array}$ & $\begin{array}{l}\text { Warna } \\
\text { dominan putih } \\
\text { dan motif } \\
\text { endek } \\
\text { pepatran warna } \\
\text { pastel }\end{array}$ & $\begin{array}{l}\text { Warna dominan } \\
\text { putih dan motif } \\
\text { endek pepatran } \\
\text { warna pastel }\end{array}$ \\
\hline Nilai & terang & terang & terang & terang & terang \\
\hline Tekstur & $\begin{array}{l}\text { Perpaduan } \\
\text { antara halus, } \\
\text { tembus pandang, } \\
\text { kusam dan kasar }\end{array}$ & $\begin{array}{l}\text { Perpaduan } \\
\text { antara halus, } \\
\text { tembus pandang, } \\
\text { bergelombang, } \\
\text { kusam dan } \\
\text { kasar }\end{array}$ & $\begin{array}{l}\text { Perpaduan } \\
\text { antara halus, } \\
\text { tembus } \\
\text { pandang, } \\
\text { kusam dan } \\
\text { kasar }\end{array}$ & $\begin{array}{l}\text { Perpaduan } \\
\text { antara halus, } \\
\text { kusam dan kasar }\end{array}$ & $\begin{array}{lr}\text { Perpaduan } \\
\text { antara halus, } \\
\text { kusam dan } \\
\text { kasar }\end{array}$ \\
\hline
\end{tabular}


Penerapan Prinsip Desain dalam Desain Busana

\begin{tabular}{|c|c|c|c|c|c|}
\hline Prinsip Desain & Desain 1 & Desain 2 & Desain 3 & Desain 4 & Desain 5 \\
\hline Kesatuan & $\begin{array}{l}\text { Harmoni dalam } \\
\text { warna dan motif }\end{array}$ & $\begin{array}{l}\text { Harmoni } \\
\text { dalam warna } \\
\text { dan motif }\end{array}$ & $\begin{array}{l}\text { Harmoni dalam } \\
\text { warna dan motif }\end{array}$ & $\begin{array}{l}\text { Harmoni } \\
\text { dalam warna } \\
\text { dan motif }\end{array}$ & $\begin{array}{l}\text { Harmoni } \\
\text { dalam warna dan } \\
\text { motif }\end{array}$ \\
\hline Keseimbangan & simetris & simetris & simetris & simetris & simetris \\
\hline Proporsi & $1: 3: 2$ & $1: 1: 2$ & $1: 3$ & $1: 2$ & $1: 2$ \\
\hline Irama & $\begin{array}{l}\text { Trama } \\
\text { pengulangan } \\
\text { warna putih } \\
\text { pada kain tule } \\
\text { putih, aplikasi } \\
\text { bordir putih, } \\
\text { bulu putih }\end{array}$ & $\begin{array}{l}\text { lrama } \\
\text { pengulangan } \\
\text { bentuk pada } \\
\text { frill tumpuk di } \\
\text { bagian lengan }\end{array}$ & $\begin{array}{l}\text { Trama } \\
\text { pengulangan } \\
\text { bentuk pada } \\
\text { motif dress } \\
\text { endek }\end{array}$ & $\begin{array}{l}\text { Trama } \\
\text { pengulangan } \\
\text { warna putih } \\
\text { cuttingan putih } \\
\text { pada bagian } \\
\text { atasan dan } \\
\text { bagian celana }\end{array}$ & $\begin{array}{l}\text { Trama } \\
\text { pengulangan warna } \\
\text { putih } \\
\text { pada inner } \\
\text { kemeja dan celana }\end{array}$ \\
\hline $\begin{array}{l}\text { Pusat } \\
\text { Perhatian }\end{array}$ & $\begin{array}{lr}\text { motif } & \text { bordiran } \\
\text { emas } & \text { pada } \\
\text { gaun } & \end{array}$ & $\begin{array}{l}\text { Frill pada } \\
\text { kedua bagian } \\
\text { lengan }\end{array}$ & $\begin{array}{l}\text { Aplikasi } \text { border } \\
\text { bunga tempel } \\
\text { putih pada } \\
\text { bagian dada }\end{array}$ & $\begin{array}{l}\text { motif endek } \\
\text { pepatran pada } \\
\text { jas }\end{array}$ & $\begin{array}{l}\text { motif bordiran } \\
\text { emas pada jas }\end{array}$ \\
\hline
\end{tabular}

\section{KESIMPULAN}

Perancangan gaun houte couture jalak Bali dengan aplikasi kain tenun endek motif pepatraan ini merupakan salah satu bentuk pengaplikasian upaya pelestarian lingkungan dan budaya Indonesia. Proses penciptaan karya juga terjadi beberapa kendala baik saat pemilihan bahan dan motif maupun proses penggarapan. sebagai bangsa yang memiliki beragam corak ragam hias, hal ini menjadi suatu kebanggaan karena memiliki kekayaan budaya yang luas. Terutama menyadari bahwa ada perkembangan dunia fashion yang memiliki potensi kreasi yang sangat besar. Suatu potensi yang mampu melahirkan kekayaan budaya yang demikian banyak dan kekayaan corak yang demikian ragamnya. Saran untuk penelitian dan penciptaan selanjutnya yaitu diharapkan untuk dapat menggali berbagai ide yang berasal dari keunggulan lokal yang dimiliki Indonesia umumnya, dan Bali khususnya, serta variasi model desain dan teknik dalam membuat busana dengan tingkatan haute couture harus dengan sangat teliti dalam proses pengerjaannya.

\section{DAFTAR PUSTAKA}

Buku :

Alfian, Mukhsin \& Ika Maryani. (2019). Ensiklopedia; Satwa Negeriku. K-Media. Yogyakarta

Barnard, Malcolm. (2011). Fashion sebagai Komunikasi Cara Mengkomunikasikan Identitas social, seksual, Kelas dan Gender. Jalasutra. Yogyakarta

Buzan, Tony. The Ultimate Book of Mind Maps atau Buku Pintar Mind Map, terjemahan 
Susi Purwoko (2005). Gramedia Pustaka Utama. Jakarta

Glebet, I Nyoman. (1986). Arsitektur Tradisional Daerah Bali. Departemen Pendidikan dan Kebudayaan. Bali Gustami, S.P. (2007). Butir-butir Mutiara Estetika Timur; Ide Dasar Penciptaan Karya.

\section{Prasistwa.Yogyakarta}

Hardisurya, Irma, dkk. (2011). Kamus Mode Indonesia. PT Gramedia Pustaka Utama. Jakarta Mas'ud, Burhanuddin. (2010). Teknik Menangkarkan Burung Jalak di Rumah. IPB Press. Bogor Pusat Data dan Analisa Tempo. (2019). Indonesia Menjaga Satwa; Melawan Ancaman Punah Hewan

\section{Langka. Tempo Publishing}

Riyanto, Arifah A. (2003). Desain Busana. Yapemdo. Bandung

Sardjana, I Komang Wiarsa \& Susilowati. (2019). Burung Jalak Bali (Leucopsar Rotschildi). Airlangga University Press. Surabaya

Sue Jenkyn Jones. (2002). Fashion Design. Laurence King Publishing. London

Widana, I Gusti Ketut. (2011). Menyoroti Etika Umat Hindu ke Pura Berpenampilan Selebritis. PT. Offset BP Denpasar. Denpasar

Tesis :

Leliana Sari, Dewa Ayu Putu. (2014). Bunga Jepun sebagai Sumber Ide dalam Penciptaan Adi Busana (Haute
Couture), Tesis Tidak Dipublikasikan. Program Pasca Sarjana Institut Seni Indonesia Denpasar

Jurnal :

Anggun, Sza sza. (2018). Penciptaan Perhiasan; Burung Jalak Bali sebagai Sarana Edukasi Masyarakat dalam Jurnal Kriya Seni, UPT. Perpus ISI Yogyakarta. Diperoleh tanggal 29 April 2021, dari situs http://digilib.isi.ac.id/4200/

Ardhana, I Putu Gede \& Nana Rukmana. (2017). Keberadaan Jalak Bali (Leucopsarrothschildi Stresemann 1912) Di Taman Nasional Bali Barat. dalam Jumal SIMBIOSIS V (1). Jurusan Biologi Universitas Udayana. Diperoleh pada tanggal 3 Juli 2021, dari situs DOI

: https://doi.org/10.24843/JSIMBIOSIS.2017.v05. i01.p01

Ariati, Ni Luh Desi, dkk. (2018). Pengembangan Busana Pesta Malam dengan Sumber Ide Busana Ratu Elizabeth Kerajaan Inggris. Dalam Jurnal Bosaparis: Pendidikan Kesejahteraan Keluarga, Volume 9, Nomor 3, November 2018. Diperoleh tanggal 2 Juli 2021, dari situs https://ejournal. undiksha.ac.id/index.php/JJPKK/article/ download/22147/13767

Aryanti, Nirmala Ayu dan Reyza Hermawan, (2018). Karakteristik Pemanfaatan Pohon oleh Jalak Bali

(Leucosar Rothclidi) di Taman Nasional Bali 
Wilayah SPTN III Buleleng, Bali. Yuliantara, IW, dkk. (2018). Analisis Habitat dalam jurnal

BIOTROPIKA, Journal of Tropical Biology,

$\mathrm{VI} / 1$. Jurusan Biologi FMIPA

Universitas

Brawijaya:.Surabaya. Diperoleh tanggal 29 April 2021, dari situs https://biotropika.ub.ac.id/index. php/biotropika/article/download/443/282

Putra, I Komang Andhika, dkk. (2014). Perilaku Harian Burung Jalak Bali (Leucopsar Rotschildi)

Periode Breeding) pada Relung yang Berbeda di Bali Bird Park, Gianyar Bali. Dalam Jurnal Biologi Volume 18 No 1 Juni 2014. Diperoleh tanggakl 3 Juli 2021, dari situs https://ojs.unud.ac.id/index. php/BIO/article/view/12087

Putri, Sabrina Dima \& Marissa Agustina Cory Siagian. (2018). Perancangan Busana Demi-Couture dengan Motif Inspirasi Obsevatorium Bosscha. e-Proceeding of Art \& Design : Vol.5, No.3 Desember 2018. Diperoleh tanggal 1 Juli 2021, dari situs https://openlibrary.telkomuniversity. ac.id/pustaka/146677/perancanganbusana-demi-couture-dengan-inspirasiarsitektur-observatorium-bosscha.html.

Suparta, I Made. (2010). Jenis Hiasan Tatahan Bade. Dalam Jurnal IMAJI, Vol. 8, No.1, Februari 2010.Diperoleh tanggal 1Juli 2021, dari situs

https://journal.uny.ac.id/index.php/imaji/article/ download/6651/5711 dan Populasi Jalak Bali (Leucopsar Rotschildi) di Resort Teluk Brumbun Taman Nasional Bali Barat. dalam Jurnal Pendidikan Biologi Undiksha. Volume 5 Nomor 1 Tahun 2018, Jurusan Biologi FMIPA Undiksha. Singaraja Bali. Diperoleh tanggal 2 Juli 2021, dari situs https://ejournal.undiksha.ac.id/index. php/JJPB/article/view/21932

\section{Internet :}

https://id.wikipedia.org/wiki/Jalak_bali (diakses pada 27 Februari 2021)

Triajatnika, (2017). Retrieved 3 Juli 2021. From https://triasuwardi.wordpress. com/2017/01/22/adibusana-trend-danfashion-designer/ 